\title{
Tumores epidermóides e dermóides do sistema nervoso central: experiência com 17 casos
}

\author{
José Carlos Lynch¹, Ricardo Andrade², Celestino Pereira³, Lygia Câmara4 \\ Hospital dos Servidores do Estado (HSE), Rio de Janeiro, RJ, Brasil
}

\section{RESUMO}

Objetivo: Analisar 17 casos de tumores epidermóides e dermóides do neuroeixo tratados nos últimos 20 anos no Hospital dos Servidores do Estado do Rio de Janeiro. Método: Estudo retrospectivo que analisa as manifestações clínicas, os aspectos de imagem e os resultados do tratamento cirúrgico. Resultados: Houve nítido predomínio dos tumores epidermóides (13:4), com a localização intracraniana sendo a mais comum, principalmente nas regiões parasselar, do ângulo pontocerebelar e no interior do quarto ventrículo. Foi possível a remoção completa em 15 dos 17 casos, com excelente resultado. Conclusão: A remoção total desses tumores sem provocar danos às estruturas neurovasculares é possível por meio de meticulosa técnica microneurocirúrgica, porém, quando a lesão se estende anteriormente ao tronco cerebral, a remoção subtotal é a escolha correta, conforme optamos em um dos casos.

\section{PALAVRAS-CHAVE}

Tumor epidermóide. Tumor dermóide.

\begin{abstract}
Objective: Seventeen cases of epidermoid and dermoid tumors of the neuroaxis treated during the past 20 years in the Hospital dos Servidores do Estado, Rio de Janeiro, Brazil, were analyzed with regard to clinical presentation, imaging findings, and microneurosurgical treatment. Method: Retrospective study. Results: Epidermoids were predominant (13:4); the intracranial localization was the most frequent, parasselar, cerebelopontine angle and in the fourth ventricle being preferential locations. Complete removal of the lesion was achieved in fifteen of the patients, without morbidity. Conclusion: Meticulous microsurgical technique allows a complete removal of such lesions without damage to surrounding neurovascular structures. Subtotal resection carries a high incidence of recurrence, so radical microsurgical resection should be attempt, but whem the lesion reaches the anterior aspect of the brain stem as in one of our cases, the subtotal removal is an acceptable option.
\end{abstract}

\section{KEY WORDS}

Epidermoid tumors. Dermoid tumors.

\section{Introdução}

Os tumores epidermóides e dermóides que afetam o sistema nervoso central (SNC) são infreqüentes. Os tumores epidermóides intracranianos correspondem a menos de $1 \%$ de todos os tumores desse segmento; os dermóides são ainda mais raros. Quando sua localização é intrarraquiana, estes constituem $0,5 \%$ de todos os tumores, com os epidermóides aparecendo de maneira ainda mais $\operatorname{rara}^{2,6,7,12,13,14,16,17,19,21}$.
Pela escassa ocorrência dessas lesões e pelo fato de as publicações em língua portuguesa referentes a elas serem ocasionais ${ }^{2,11,14}$, decidimos rever e apresentar nossa experiência no manejo de 17 casos que apresentaram esses tipos de tumores.

\section{Casuística e método}

Entre os anos de 1986 e 2005, 17 casos de tumores dermóides e epidermóides localizados no SNC foram

1 Chefe do Serviço de Neurocirurgia do Hospital dos Servidores do Estado do Rio de Janeiro (HSE).

2 Chefe de Clínica do Serviço de Neurocirurgia do HSE.

3 Neurocirurgião do HSE.

4 Patologista do HSE. 
diagnosticados e tratados no Hospital dos Servidores do Estado do Rio de Janeiro. Os prontuários e os exames diagnósticos e anatomopatológicos foram revistos. $\mathrm{O}$ seguimento desses pacientes variou de 4 meses a 20 anos, com média de 6,5 anos.

\section{Resultados}

Nesta série, encontramos 10 homens e 7 mulheres. A idade variou de 1 a 73 anos, com média de 30,4 anos.

Treze lesões foram diagnosticadas como epidermóides e quatro como dermóides; dez eram intracranianas, quatro intradiplóicas e três intrarraquianas. Entre os intracranianos, quatro se situavam no ângulo pontocerebelar (APC), dois se alojavam na região parasselar, dois se encontravam no interior do quarto ventrículo, um no cerebelo e outro na região frontoparietal.

$\mathrm{O}$ quadro clínico desses pacientes apresentou-se variado. Quando as lesões se situavam no APC, registramos variações da síndrome. No caso dos tumores que se localizavam na região parasselar, a manifestação clínica era relacionada à compressão do nervo ou do quiasma óptico e/ou à crise convulsiva. Nos dois pacientes com lesões intraventriculares, síndrome de hipertensão intracraniana foi diagnosticada. Quando eram intradiplóicos, a queixa era de abaulamento localizado. Naqueles casos de localização intrarraquiana, a manifestação neurológica encontrada foi de paraparesia com alterações esfincterianas. Defeitos de fechamento do tubo neural foram detectados nos três pacientes com a lesão intrarraquiana. Dois apresentavam sínus dermal e outro, talo lipofibromatoso.

Dos 17 pacientes do presente estudo, 16 foram submetidos à remoção microcirúrgica de suas lesões. Somente em 1 paciente (caso no 6) decidimos pelo acompanhamento clínico, visto que o sintoma era mínimo. Dos 16 pacientes operados, obtivemos a remoção total da lesão, sem provocar novos déficit neurológicos (resultado considerado excelente), em 15; em 1 (caso no 1 ), conseguiu-se apenas a remoção parcial, também sem déficits neurológicos (resultado considerado bom). Não houve óbito nesta série.

Os dados demográficos, os sintomas e as características dos tumores são apresentados na tabela 1 .

\begin{tabular}{|c|c|c|c|c|c|c|}
\hline № & Idade/sexo & Local & $\begin{array}{l}\text { Sinais } \\
\text { Sintomas }\end{array}$ & Remoção & Resultado & Diagnóstico \\
\hline 1 & $52 / \mathrm{M}$ & $\mathrm{APC}$ & $\begin{array}{l}\text { Ataxia } \\
\text { Surdez }\end{array}$ & Parcial & Bom & Epidermóide \\
\hline 2 & $23 / \mathrm{F}$ & $4^{\circ}$ ventrículo & $\mathrm{HIC}$ & Total & Excelente & Epidermóide \\
\hline 3 & $47 / \mathrm{M}$ & $\mathrm{APC}$ & $\begin{array}{l}\text { Ataxia } \\
\text { Surdez }\end{array}$ & Total & Excelente & Epidermóide \\
\hline 4 & $73 / \mathrm{F}$ & APC & Ataxia & Total & Excelente & Epidermóide \\
\hline 5 & $35 / \mathrm{F}$ & Parasselar & $\begin{array}{l}\text { Convulsão } \\
\text { Déficit visual }\end{array}$ & Total & Excelente & Epidermóide \\
\hline 6 & $13 / F$ & APC & Tinitus & Não removido & - & Epidermóide \\
\hline 7 & $25 / \mathrm{M}$ & Cerebelar & $\begin{array}{l}\text { S. dermal } \\
\text { Meningite }\end{array}$ & Total & Excelente & Dermóide \\
\hline 8 & $47 / \mathrm{M}$ & Lombar & $\begin{array}{l}\text { Escoliose } \\
\text { Paraparesia }\end{array}$ & Total & Excelente & Dermóide \\
\hline 9 & $28 / \mathrm{M}$ & Lombar & Paraparesia & Total & Excelente & Epidermóide \\
\hline 10 & $10 / \mathrm{M}$ & Torácico & $\begin{array}{l}\text { S. dermal } \\
\text { Meningite }\end{array}$ & Total & Excelente & Dermóide \\
\hline 11 & $12 / \mathrm{M}$ & ID & Abaulamento & Total & Excelente & Epidermóide \\
\hline 12 & $22 / \mathrm{F}$ & $4^{\circ}$ - ventrículo & $\mathrm{HIC}$ & Total & Excelente & Epidermóide \\
\hline 13 & $43 / \mathrm{M}$ & Parasselar & Convulsão & Total & Excelente & Epidermóide \\
\hline 14 & $57 / \mathrm{M}$ & Parietal & Hemiparesia & Total & Excelente & Epidermóide \\
\hline 15 & $22 / \mathrm{F}$ & ID & Abaulamento & Total & Excelente & Dermóide \\
\hline 16 & $10 / \mathrm{F}$ & ID & Abaulamento & Total & Excelente & Epidermóide \\
\hline 17 & $1 / \mathrm{M}$ & ID & Abaulamento & Total & Excelente & Epidermóide \\
\hline
\end{tabular}

APC: ângulo pontocerebelar; F: feminino; HIC: hipertensão intracraniana; ID: intradiplóico; M: masculino; S: sínus. 


\section{Discussão}

\section{Epidemiologia}

Os tumores epidermóides são lesões infreqüentes. Quando estão localizados na cavidade intracraniana, correspondem a menos que 1\% dos tumores. Os dermóides são mais raros. Na raque, os tumores dermóides representam $0,5 \%$ dos tumores da região. Os epidermóides, por sua vez, são ainda menos freqüentes ${ }^{2,6,7,11,12,13,14,16,17,19,21 . ~}$

\section{Patogênese}

Os tumores epidermóides e dermóides têm origem embriológica. Os primeiros são constituídos por restos da epiderme aprisionados no interior do SNC no momento do fechamento do tubo neural, entre a terceira e a quinta semanas de vida do embrião. Nos tumores dermóides, ocorre a retenção de restos da derme $e^{3,6,12,13,21}$. Os tumores epidermóides podem, eventualmente, se desenvolver a partir da inclusão de células epiteliais em decorrência de punções lombares repetidas, como no tratamento da meningite tuberculosa e no afundamento de crânio ${ }^{11,12}$.

\section{Patologia}

O tumor epidermóide é constituído por células epiteliais descamadas, queratina e colesterol provenientes do epitélio escamoso estratificado. Apresentam aspecto perolado $2,3,6,12,13$. Ocasionalmente, pode ocorrer transformação maligna (carcinoma de células escamosas) ${ }^{1,7,9}$.

O tumor dermóide, por sua vez, é constituído por fâneros da pele (cabelos, glândulas sebáceas e sudoríparas) e tecido adiposo ${ }^{11,13}$. O crescimento desses tumores é muito lento: ocorre por acúmulo de células epiteliais escamadas, com velocidade semelhante à da renovação da pele. Alguns autores os classificam como hamartomas e não como neoplasias verdadeiras ${ }^{2,21}$ (figura 1).

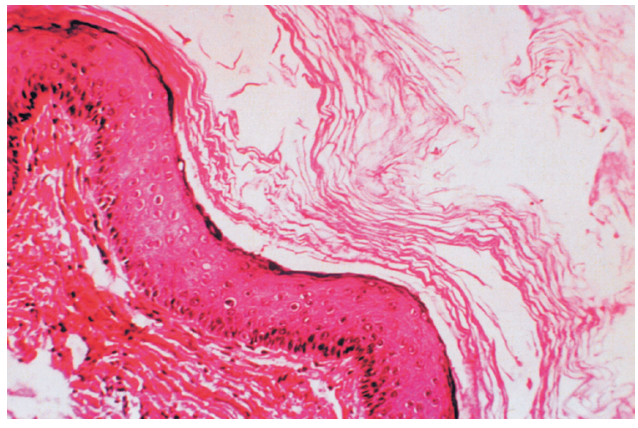

Figura 1 - Tumor epidermóide, fotomicorgrafia $(H \& E)$ : células epiteliais descamadas, queratina e pseudocápsula.

\section{Quadro clínico}

As manifestações neurológicas variam de acordo com a localização da lesão, porém, algumas peculiaridades são características desses tumores. Cinqüenta por cento dos tumores epidermóides intracranianos localizam-se no APC e correspondem a $6 \%$ de todos os tumores nesse sítio. Aí, com freqüência, a neuralgia do trigêmeo ou o espasmo hemifacial é associado aos tumores epidermóides, principalmente em pacientes jovens ${ }^{2,8,9,18,19}$. Tais sintomas foram encontrados em dois pacientes da presente série.

Quando as lesões se situam no eixo raquiano, observam-se paraparesia e alterações esfincterianas. É também freqüente a associação com defeitos de fechamento do tubo neural, como a mielomeningocele, o sínus pilonidal, o sínus dermal, etc. Quando ocorre a presença de sínus dermal, o paciente pode desenvolver quadros de meningite bacteriana de repetição ${ }^{4,9,10,12,13,14}$ (esse fato ocorreu em dois pacientes). Deve ser diferenciada da meningite química, ou da meningite colesterínica, que ocorre quando os cristais de colesterol que existem no interior do tumor epidermóide extravasam para o espaço subaracnóideo, provocando reação inflamatória ${ }^{12,13,14}$.

\section{Diagnóstico por imagem}

Nos casos em que o tumor epidermóide é de localização intradiplóica, a radiografia simples do crânio revela lesão lítica, circunvolta por um halo esclerótico ${ }^{9}$. Quando são intracranianos, a tomografia computadorizada (TC) de crânio identifica lesão hipodensa, com densidade semelhante à do liquor, com bordos nítidos, de forma arredondada e superfície lobulada, ocupando e infiltrando as cisternas basais. Pode conter calcificações em $10 \%$ a $25 \%$ dos casos. Não há captação do contraste venoso; quando isso ocorre, pode significar transformação maligna. A ressonância magnética detecta lesão hipointensa em T1 e hiperintensa em T2, com características semelhantes às do líquido cefalorraquidiano. $\mathrm{O}$ diagnóstico diferencial mais importante, e muitas vezes difícil, é com o cisto aracnóideo. Todavia, nos tumores epidermóides, as aquisições da ressonância em difusão revelam sinal hiperintenso, semelhante ao parênquima cerebral, ou seja, o sinal hiperintenso se mantém. No cisto aracnóideo, tal fato não se dá.

Alguns tumores epidermóides podem se apresentar iso ou mesmo hiperintensos nas imagens ponderadas em T1 e T2, sendo denominados de epidermóides brancos. Isso acontece pelo alto teor protéico em seu interior. Da mesma forma, devemos diferenciá-los da megacisterna, dos lipomas, dos astrocitomas císticos e de outros tumores císticos $2,5,6,14,18$ (figuras 2 e 5). 

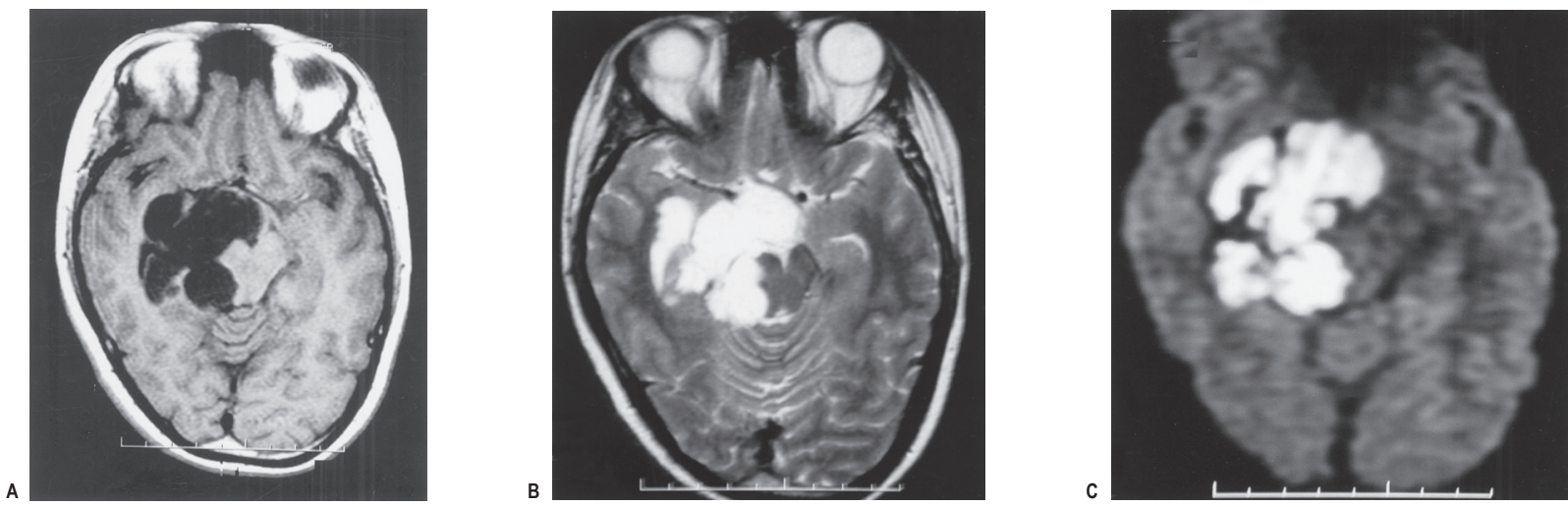

Figura 2 - RM de tumor epidermóide parasselar (caso 5): A) na aquisição T1, lesão hipointensa; B) em T2, lesão hiperintensa; C) na difusão, lesão hiperintensa.
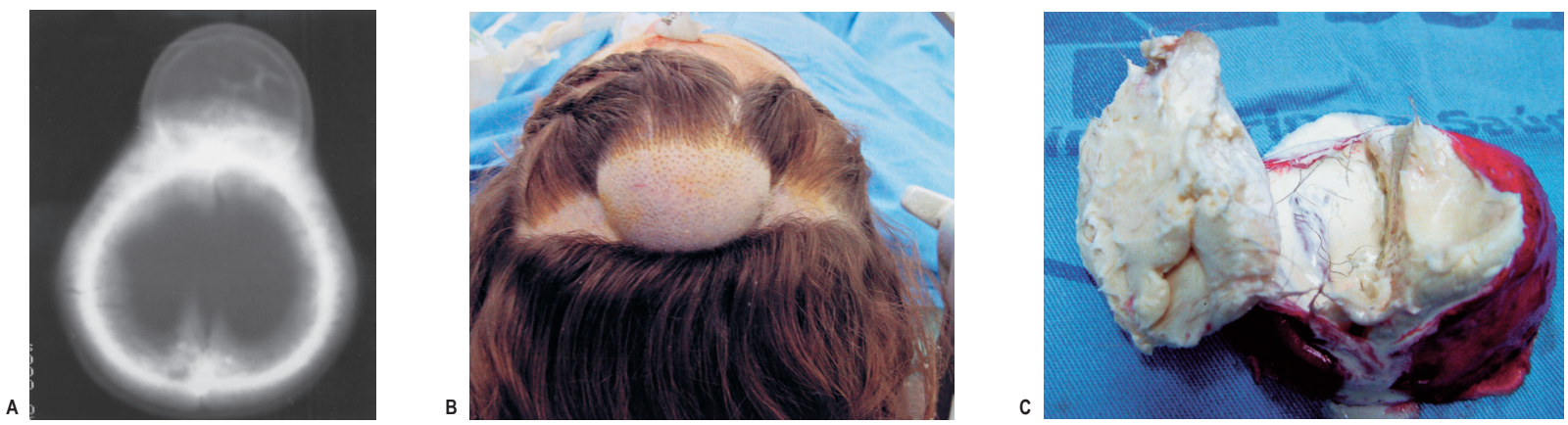

Figura 3 - TC de tumor dermóide (caso 15): A) abaulamento frontal hipodenso; B) aspecto da lesão antes da cirurgia; C) a lesão foi seccionada, revelando aspecto peroláceo e tufos de cabelos em seu interior.

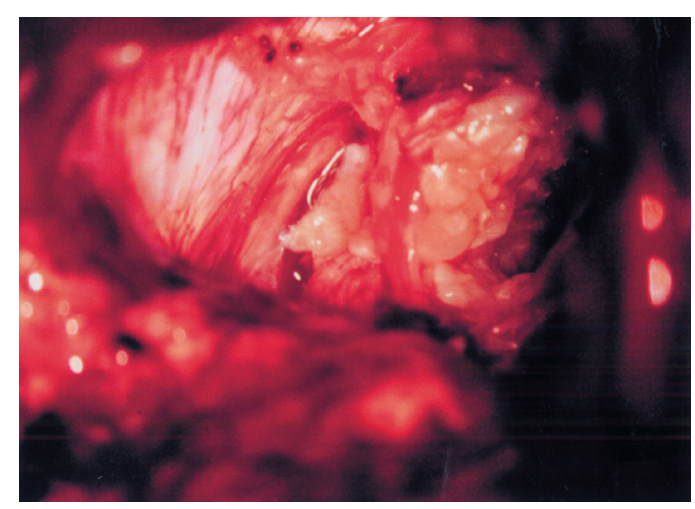

Figura 4-Tumor epidermóide. Aspecto inicial da cirurgia. Paciente em posição semi-sentada, tumor ocupando o APC esquerdo. Notar os nervos cranianos VII e VIII (caso 1, remoção parcial).

\section{Tratamento}

O tratamento dos tumores epidermóides e dermóides é essencialmente cirúrgico. Em pacientes idosos, com quadro clínico instável, ou ainda em pacientes assintomáticos ou com sintomas mínimos, a conduta expectante pode ser instituída. Esses pacientes devem ser acompanhados com exames de imagem repetidos, com o intuito de observar a evolução da lesão $0^{2,6,8,14,18,19,20}$.

Sob o microscópio cirúrgico, o tumor se revela peroláceo, de consistência macia, disposto em camadas sobrepostas, facilmente dissecáveis com o microdissector e progressivamente removíveis com a pinça adequada. Sangramento importante não é observado ${ }^{2,14,18,19,20}$ (figuras 3, 4 e 6).

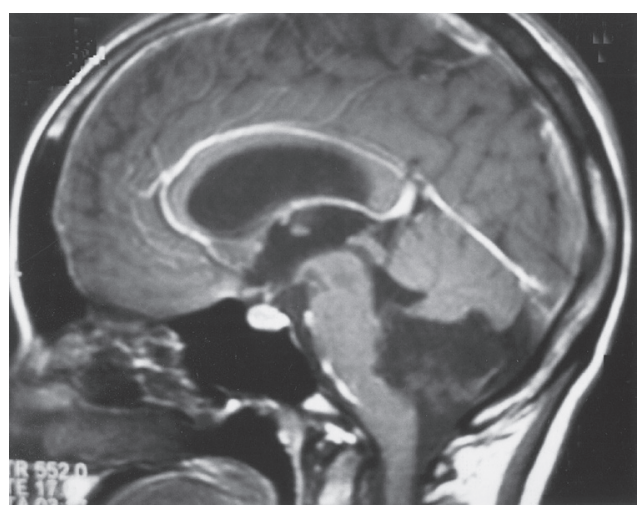

Figura 5-RM, em T1, de tumor epidermóide ocupando a cisterna magna e invadindo o quarto ventrículo sob forma de lesão hipodensa (caso 12). 

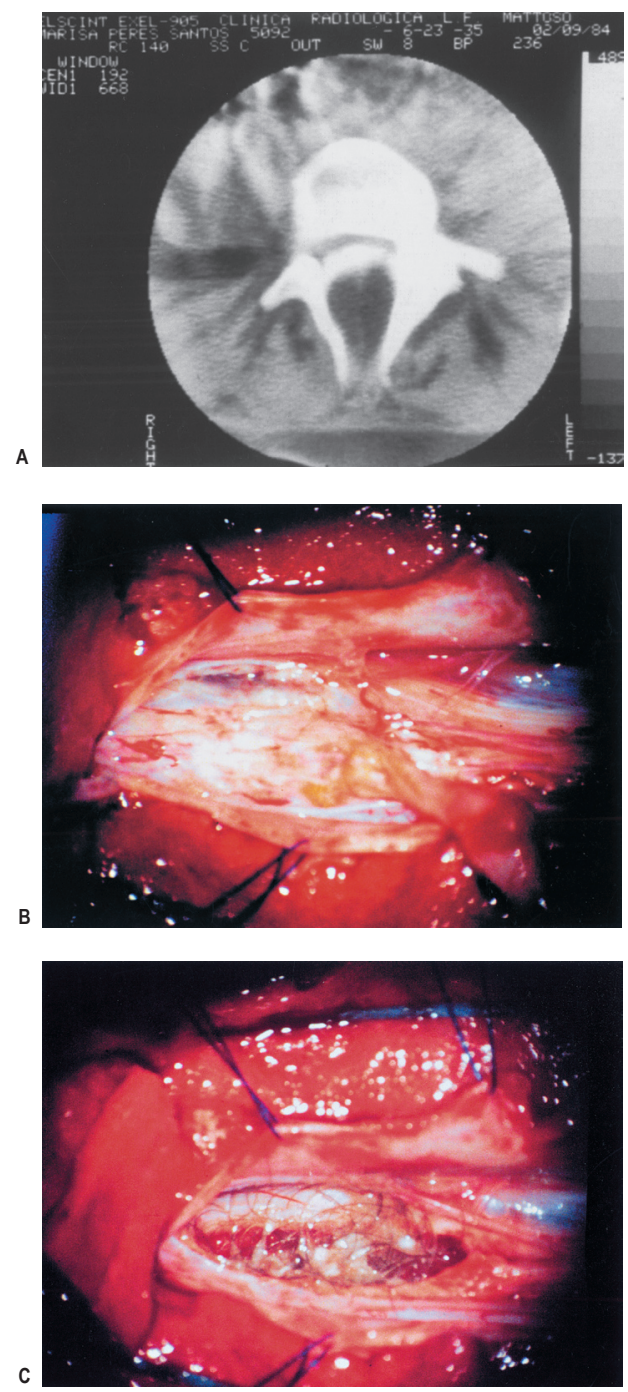

Figura 6-A) TC de coluna demonstrando lesão hipodensa intrarraquiana e espinha bífida (caso 8); B) microfotografia do talo fibrolipomatoso dissecado até a medula; C) tumor dermóide intradural pós-secção do talo fibrolipomatoso.

Como o tumor se difunde pelas cisternas basais, com freqüência envolve e se adere às estruturas neurovasculares. Estas devem ser dissecadas do tumor de forma delicada. Quando o tumor epidermóide se localiza no APC, freqüentemente se insinua entre a artéria basilar e a protuberância, envolvendo artérias perfurantes; a tentativa de remoção do tumor pode provocar ruptura desses vasos, com graves lesões neurológicas. Para alguns autores, o tumor epidermóide apresenta uma pseudocápsula, ou seja, uma aracnóide espessada causada pela resposta ao processo inflamatório crônico. Outros autores acreditam que essa parede seja constituída pelo epitélio escamoso estratificado.

Existe uma controvérsia em relação à necessidade da remoção total dessa cápsula. Certos autores afirmam que a sua retirada pode resultar em seqüelas neuroló- gicas decorrentes de lesões neurovasculares, enquanto outros autores enfatizam que a não remoção da cápsula fatalmente levará à recidiva tumoral ${ }^{2,8,14,18,20}$.

Em nossa experiência, sempre tentamos remover totalmente a cápsula, a não ser que a encontremos muito aderida às estruturas neurais ou vasculares. Durante a remoção tumoral, deve-se proteger o espaço subaracnóideo com cotonóides e irrigações sucessivas com soro fisiológico para evitar o aparecimento de meningite colesterínica. O uso de cortisona venosa durante e após o ato cirúrgico bloqueia os efeitos da irritação química.

Nos tumores do APC, a craniectomia retrossigmóidea é adequada. Quando o tumor se localiza na região parasselar, o acesso pterional é excelente. Caso os tumores sejam de localização intrarraquiana, com freqüência são associados a defeitos de fechamento da linha média, como sínus dermal ou pilonidal, ou talo fibrolipomatoso ${ }^{4,11,15}$. Em tais situações, é necessário remover tanto a lesão superficial como a intradural, procedimento realizado com técnicas microcirúrgicas adequadas (figura 6).

\section{Conclusão}

Os tumores epidermóides e dermóides que envolvem o SNC são raros. Em nossa casuística, observamos que os tumores epidermóides intracranianos são mais freqüentes que os dermóides. A idade média nesta série foi de 30,7 anos.

Quando apresentam sinais e sintomas, devem ser submetidos à remoção microcirúrgica, de modo a se obter a retirada total da lesão. A cirurgia é de baixo risco, e nesse grupo de pacientes não ocorreu nenhum óbito, porém, quando os tumores estão localizados no APC, a morbidade pode ser alta devido à grande aderência do tumor aos nervos cranianos.

\section{Referências}

1. ABRAMSON RC, MORAWETZ RB, SCHLITT M: Multiple complications from on intracranial epidermoid cyst: case report and literature review. Neurosurgery 24:574-8, 1989.

2. AGUIAR PHP, ROTTA JM, PEREIRA CU: Cistos epidermóides cranianos. In Pereira CU, Aguiar PHP, Ramina R (eds): Tópicos em Neurocirurgia. Rio de Janeiro, Revinder, 2001, pp 53-7.

3. ALVORD Jr EC: Growth rates of epidermoid tumors: Ann Neurol 2: 367-70, 1977.

4. BORGES AC, FESTOGATU RR, DUVAL NETO GF, ZAUK $A D$ : Distúrbios esfincterianos secundários a tumor epidermóide intramedular. Arq Neuropsiquiatr (S Paulo) 38: 308-11, 1980. 
5. FEIN JM, LIPOW K, TAATI F, LANSEM T: Epidermoid tumor of the cerebellopontine angle: Diagnostic value of computed tomografic metrizamide cisternografy. Neurosurgery 9: 179-82, 1981.

6. GELABERT-GONZÁLES M, GARCÍA-ALLUT A, MARTÍNEZ-RUMBO R: Quiste epidermoide de tercer ventrículo. Neurocirurgia 13:389-92, 2002.

7. GOLDMAN SA, GANDY SE: Squamous cell carcinoma as a late complication of intracerebroventricular epidermoid cyst. J Neurosurg 66: 618-20, 1987.

8. KOBATA H, KONDO A, IWASAKI K: Cerebellopontine angle epidermoids presenting with cranial nerve hyperactive dysfunction: pathogenesis and long-term surgical results in 30 patients. Neurosurgery 50:276-85, 2002.

9. LINK MJ, COHEN PL, BRENEMAN JC, TEW Jr JM: Malignant squamous degeneration of a cerebellopontine angle epidermoid tumor. Case report. J Neurosurg 97:1237-43, 2002.

10. MacCARTY CS, LEAVENS ME, LOVE JG, KERNOHAN JW: Dermoid and epidermoid tumors in the central nervous system of adults. Surg Gynecol Obstet 108:191-8, 1959.

11. ROCHA Jr MA, CARVALHO GTC, FARIA MP, FAGLIONI Jr $\mathrm{N}$, SOUZAAA: Tumor epidermóide intramedular. Relato de caso. Arq Neuropsiquiatr 61 (3-B):867-9, 2003.

12. RUBISTEIN LJ: Tumor of the nervous system. Washington D.C., Armed Forces Institute of Pathology, 1970, pp 285-92.

13. RUSSELL DS, RUBISTEIN LJ: Pathology of tumours of the nervous system. 4.ed., Baltimore, Willians and Wilkins, 1977, pp 28-32.

14. SOUZA HL, CALDAS JBR, MENGUITA LG, PEREIRA HSG, MOURA JAS, BATISTA AL et al: Tumor epidermóide intracraniano: relato de dois casos e revisão da literatura. J Bras Neurosurg 10:66-71, 1999.
15. TEKKÖK IH, PALAOGLU S, ERBENGI A, ÖNOL B: Intramedullary epidermoid cyst of the cervical spinal cord associated with na extraspinal neuroenteric cyst: case report. Neurosurgery 31:121-6, 1992.

16. TOGLIA JU, NETSKY MG, ALEXANDER Jr E: Epithelial (epidermoid) tumors of the cranium. J Neurosurg 23:384-93, 1965.

17. TYLUS JS, PENNYBACKER J: Pearly tumours in relation to the central nervous system. J Neurol Neurosurg Psychiatry 19:241-59, 1956.

18. VINCHON M, PERTUZON B, LEJEUNE JP, ASSAKER R, PRUVO JP, CHRISTIAENS JL: Intradural epidermoid cysts of the cerebellopontine angle: diagnosis and surgery. Neurosurgery 36:52-7, 1995.

19. YAMAKAWA K, SHITARA N, GENKA S, MANAKA S, TAKAKURA K: Clinical course and surgical prognosis of 33 cases of intracranial epidermoid tumours. Neurosurgery 24:568-73, 1989.

20. YASARGIL MG, ABERNATHEY CD, SARIOGLU AC: Microneurosurgical treatment of intracranial dermoid an epidermoid. Neurosurgery 24:561-7, 1989.

21. ZÜLCH KJ: Brain tumours. Their biology and pathology. 2.ed. New York, Springer, 1965, pp 240-565.

Original recebido em abril de 2006

Aceito para publicação em julho de 2006

\section{Endereço para correspondência:}

José Carlos Lynch

Rua Jardim Botânico, 600 - sala 605

22461-000 - Rio de Janeiro, RJ

E-mail: cneuroamericas@uol.com.br 